\title{
Percepções acerca da produção acadêmica docente em Instituições de Ensino Superior brasileiras
}

\section{Perceptions about the professors' academic production in brazilian Higher Education Institutions}

Percepciones acerca de la producción académica docente en Instituciones de Enseñanza Superior brasileñas

\author{
Alexey Carvalho ${ }^{1}$ \\ Maria Alzira de Almeida Pimenta²
}

DOI: http://dx.doi.org/10.20435/serie-estudos.v22i45.1073

\begin{abstract}
Resumo: O cenário que envolve a Educação Superior Brasileira é marcado pela forte expansão de Instituições de Ensino Superior (IES) com vistas à ampliação da oferta de cursos de graduação. 0 foco quase que exclusivo na atividade de ensino, faz com que a atividade de pesquisa, mesmo sendo requisito legal, seja relegada a um segundo plano, de forma a desestimular a produção acadêmica docente na graduação. O presente artigo tem como objetivo apresentar e discutir as percepções acerca da produção acadêmica docente, assim como seus fatores de influência, no contexto do ensino de graduação presencial de IES brasileiras. Para atingir os objetivos propostos, partiu-se do referencial teórico sobre as questões que envolvem a pesquisa acadêmica, seu ambiente e suas condições; realizou-se um estudo de campo com docentes da educação superior, compondo uma amostra aleatória e de perfil heterogêneo, com respondentes de todas as regiões brasileiras e de IES públicas e privadas, por meio de questionário estruturado on-line. Na apresentação e análise dos resultados, buscou-se um entendimento abrangente sobre os principais aspectos que cercam a produção acadêmica docente em IES. Dentre os pontos mais relevantes, evidenciou-se de forma geral: falta de clareza nas políticas e ações de estímulo à pesquisa e à produção acadêmica, por parte das IES; e dificuldade em organizar o tempo para a pesquisa, o que indica que o aumento simplesmente de carga horária para esse fim pode não surtir efeitos. Dessa forma, os resultados do estudo podem enriquecer as discussões sobre o tema e fornecer subsídios que possam contribuir com as IES que anseiem a melhoria da produção acadêmica docente.
\end{abstract}

Palavras-chave: produção acadêmica; pesquisa; Educação Superior.

Abstract: The scenario involving the Brazilian Higher Education, marked by strong expansion of Higher Education Institutions (IES) aiming to increase the supply of undergraduate. The almost exclusive

\footnotetext{
${ }^{1}$ Universidade Anhanguera de São Paulo, São Paulo, Brasil.

${ }^{2}$ Universidade de Sorocaba (UNISO), Sorocaba, São Paulo, Brasil.
} 
focus on teaching activity, makes the research activity, even being legal requirement, is relegated to the background in order, which ends up discouraging the professors' academic production at the undergraduate. This paper is aims to present and discuss the perceptions about of professors' academic production, as well as their influencing factors in the context of campus undergraduate teaching brazilian IES. To achieve the proposed goals, starting by referential theoretical on issues involving academic research, their environment and their conditions, was performed out a field study with higher education professors, creating a random sample and heterogeneous profile with respondents from all regions Brazilian, including public and private IES, through structured questionnaire online. In the presentation and analysis of results, we sought a comprehensive understanding of the main issues surrounding the professors' academic production in IES. Among the most relevant points, it was evident in general: lack of clarity in policies and actions to stimulate research and academic production by the IES; and difficulty in organizing the time to the research, which indicates that simply increasing the workload for this purpose may not have any effect. Thus, the study results can enrich the discussions on the subject and provide subsidies that can contribute to the IES that want to improve the professors' academic production.

Key words: academic production; research; Higher Education.

Resumen: El escenario que involucra a la Educación Superior Brasileña, marcado por la fuerte expansión de Instituciones de Educación Superior (IES) con vistas a la ampliación de la oferta de carreras y programas de graduación. El enfoque casi exclusivo en la actividad de enseñanza, hace que la actividad de investigación, aun siendo requisito legal, sea relegada a un segundo plano, de forma a desalentar la producción académica de profesores en la graduación. El presente artículo tiene como objetivo presentar y discutir las percepciones acerca de la producción académica de profesores, así como, sus factores de influencia, en el contexto de graduación de IES brasileñas. Para alcanzar los objetivos propuestos, se empezó por el referencial teórico acerca de las cuestiones que involucran la investigación académica, su ambiente y sus condiciones, se realizó un estudio de campo con profesores de la educación superior, haciendo una muestra aleatoria con perfil heterogéneo, con respondedores de todas las regiones brasileñas y de IES públicas y privadas, a través de un cuestionario estructurado on-line. En la presentación y análisis de los resultados, se ha buscado un entendimiento amplio acerca de los principales aspectos que rodean la producción académica de profesores en IES. Entre los puntos más relevantes, se evidenció de forma general: falta de claridad en las políticas y acciones de estímulo a la investigación ya la producción académica, por parte de las IES; y dificultad en organizar el tiempo para la investigación, lo que indica que el aumento simplemente de carga horaria para este fin puede no surtir efectos. De esta forma, los resultados del estudio pueden enriquecer las discusiones acerca del tema y proporcionar subsidios que puedan contribuir con las IES que anhelan la mejora de la producción académica de profesores.

Palabras clave: producción académica; investigación; Educación Superior.

\section{INTRODUÇÃO}

A legislação que dispõe sobre a regulação e supervisão da Educação Superior no Brasil define três categorias de organização das Instituições de Ensino Superior (IES): Universidades, Centros Universitários e Faculdades. Em linhas gerais, a atividade de pesquisa caberia às Universidades, em especial, aos programas de pós-graduação 
stricto sensu, porém, dos docentes de graduação também é esperado que tenham produção acadêmica. Essa expectativa é gerada uma vez que, nas avaliações periódicas dos cursos, o desenvolvimento de pesquisas que gerem publicações é considerado.

Nos últimos anos, de acordo com dados do censo da Educação Superior de 2001 a 2012 (INSTITUTO NACIONAL DE ESTUDOS E PESQUISAS EDUCACIONAIS ANÍSIO TEIXEIRA [INEP], 2012), a educação superior brasileira viveu forte expansão, com objetivo de ampliar o ingresso de estudantes, tendo como foco central a atividade de ensino. Isso fez com que a atividade de pesquisa, mesmo sendo uma exigência e um requisito legal, fosse de certa forma relegada a um segundo plano e, assim, desestimulando a produção acadêmica docente na graduação.

A pesquisa acadêmica ou produção acadêmica docente, no ambiente da graduação, propicia a construção do conhecimento com envolvimento docente e discente, sendo essencial para que a educação superior cumpra seu papel formativo. Sendo assim, a relevância da pesquisa acadêmica transcende a exigência legal e burocrática a ser avaliada nas IES. Mais ainda, transcende a codificação da produção de conhecimento em índice de produtivismo que pode determinar a ascensão na carreira para o docente. Esses aspectos, por si só, recomendam entender sua contribuição para melhora qualitativa no processo de ensino e aprendizagem.

Diante do exposto, o presente artigo propõe apresentar e discutir as percepções acerca da produção acadêmica docente, assim como seus fatores de influência, no contexto do ensino de graduação presencial de IES brasileiras. Esse trabalho é parte da tese de doutoramento do primeiro autor, cuja pesquisa foi aprovada pelo Comitê de Ética em Pesquisa, da Universidade de Sorocaba, com o protocolo n. 46529115.5.0000.5500. Para atingir os objetivos, além da pesquisa bibliográfica sobre o tema, foi realizado um estudo de campo, aplicando questionário para captar as impressões e percepções dos pesquisados, docentes de ensino superior, acerca das questões e condições que envolvem a atividade de pesquisa na graduação em IES brasileiras.

Os resultados apresentados podem subsidiar as discussões sobre as políticas de incentivo à produção acadêmica docente e as estratégias possíveis para sua meIhoria e ampliação.

\section{PESQUISA E PRODUÇÃO DE CONHECIMENTO}

Especialista em avaliação na educação superior, Dias Sobrinho (2000, p. 50) afirma que "ensinar sem pesquisar afasta da realidade; pesquisar sem ensinar 
esclerosa; pesquisar ou ensinar sem vinculação com o meio elitiza", reforçando a relevância da pesquisa para a atuação docente e sua indissociável relação com a atividade de ensino ${ }^{3}$.

Produzir conhecimento e divulgá-lo em artigos vem ao encontro da busca pela excelência, ou seja, pelo alto grau de qualidade na formação ofertada. Isto acontece porque a prática pedagógica é diversificada, ampliada e aprofundada tanto do ponto de vista do docente quanto dos discentes, ao longo do processo de ensino aprendizagem. Endossando o exposto, Demo (1996) afirma que não se pode dar aula daquilo que não se produz, pois produzir conhecimento é o fundamento primeiro do docente, razão pela qual a docência começa na produção dos conteúdos de sua própria disciplina.

Acredita-se que a participação docente na produção acadêmica, paralelamente ao constante esforço para melhoria do processo ensino-aprendizagem, constitui uma necessidade para o desenvolvimento geral da sociedade. Considera-se que o desenvolvimento virá ao se assegurar a formação superior alinhada à concepção de educação como um triplo processo de hominização, socialização e singularização, conforme Charlot (2001). Além disso, Demo (1996) observa que desconsiderar a necessidade da produção do conhecimento como postura investigativa limita a educação superior, comprometendo sua competência e responsabilidade em lidar com o conhecimento novo, obstruindo sua criticidade e sua criatividade para inovar.

A Lei de Diretrizes e Bases da Educação (LDB), Lei 9.394 de 1996 (BRASIL, 1996) dispõe em seu artigo 45 que "A educação superior será ministrada em instituições de ensino superior, públicas ou privadas, com variados graus de abrangência ou especialização", não fazendo referência às possíveis categorias de organização. Além disso, define, em seu artigo 52, que as "Universidades são instituições pluridisciplinares de formação dos quadros profissionais de nível superior, de pesquisa, de extensão e de domínio e cultivo do saber humano". A caracterização da relação entre a produção intelectual e o corpo docente prevê "o estudo sistemático dos temas e problemas mais relevantes, tanto do ponto de vista científico e cultural, quanto regional e nacional". Sobre o corpo docente, está previsto que, no mínimo, um terço tenha o título de mestrado ou de doutorado e trabalhe em regime de tempo integral.

Outro aspecto importante a ser considerado, ao se pensar a produção de pesquisa, diz respeito às categorias de organização das Instituições de Ensino Superior

${ }^{3}$ Cumpre ressaltar que essa assertiva é válida para educação superior e também para educação básica. 
(IES) que são definidas pelo Decreto n. 5.773 de 2006 (BRASIL, 2006a) em seus artigos 12 e 13. O credenciamento depende da organização e das prerrogativas acadêmicas, categorizado como: Faculdades; Centros Universitários; e Universidades. Inicialmente, uma instituição é credenciada como Faculdade. A ascensão de Faculdade a Centro universitário e, posteriormente, à Universidade depende do funcionamento regular da instituição e da qualidade de seu trabalho. A gradativa ascensão traz, proporcionalmente, autonomia para gerir os aspectos administrativos, acadêmicos e pedagógicos.

A categoria específica de Centro Universitário é regulada pelo Decreto n. 5.786 de 2006 (BRASIL, 2006b). Sobre as IES que se enquadram nessa categoria, o referido Decreto, em seu artigo $1^{\circ}$, dispõe que sejam pluricurriculares, que se caracterizem "pela excelência do ensino oferecido, pela qualificação do seu corpo docente e pelas condições de trabalho acadêmico oferecidas à comunidade escolar". Entretanto só é exigido que um quinto do corpo docente trabalhe em regime de tempo integral, e um terço do corpo docente, pelo menos, tenha título de mestre ou doutor.

Percebe-se pela legislação disposta, que a atividade de pesquisa é especificada apenas na Universidade. Observa-se a falta de alinhamento com a LDB que, em seu artigo 45, estabelece, dentre as finalidades do ensino superior, a necessidade de "incentivar o trabalho de pesquisa e investigação científica, visando o desenvolvimento da ciência e da tecnologia" (BRASIL, 1996), dessa forma, abarcando todas as categorias de organização.

Com relação à regulação da educação superior, o instrumento de avaliação de cursos (INEP, 2015) definido pelo Sistema Nacional de Avaliação da Educação Superior (SINAES) aplicado nas avaliações in loco, trata de forma equânime o curso avaliado, independente da categoria de organização. Um determinado curso é avaliado da mesma forma, seja ele ofertado por uma Faculdade, Centro Universitário ou Universidade e, em todos os casos, é exigido que o corpo docente que compõe o curso tenha produção acadêmica nos últimos três anos. O que se observa na prática é uma contradição, pois não há cobrança sistemática da pesquisa das demais categorias que não a Universidade. Para além da contradição, que entendemos comprometer a avaliação e a qualidade da educação superior, neste trabalho não será feita distinção acerca da categoria de organização da IES, uma vez que, como já mencionado, a pesquisa e a produção acadêmica é necessária e importante em todas.

Para explicitar a expansão da Educação Superior no Brasil, buscou-se analisar os dados do censo da educação superior de 2001 a 2012 (INEP, 2012) e verificou-se que, nesse período, o número de IES no Brasil cresceu 74\%, passando de 1.391 para 
2.412. A expansão ocorreu tanto em IES públicas como privadas, com crescimento de cerca de $75 \%$ nas privadas e $66 \%$ nas públicas. Nas privadas, o maior crescimento absoluto se deu no número de Faculdades, passando de 1.059 para 1.898, com aumento de 79\%; já nas públicas, houve o incremento de 37 novas Universidades Federais e 14 Institutos Federais, além de oito Centros Universitários Federais.

Os dados da expansão deixam claro o estímulo à iniciativa privada, com o crescimento do número de Faculdades, por sua vez voltadas ao ensino; e a expansão pública ocorrendo majoritariamente via Universidades que, por finalidade, concentram a pesquisa. Dias Sobrinho (2010) observa a desigualdade que essa política pode produzir: as Faculdades privadas, em especial de pequeno porte, por não terem pesquisa sistemática, dificilmente beneficiarão seus estudantes com a prática da pesquisa e seus resultados. Além disso, quando egressos, por não terem desenvolvido competências em pesquisa, provavelmente, ficarão em desvantagem no mundo do trabalho e na sociedade. Lembra ainda que egressos de IES reconhecidamente de pesquisa têm melhores oportunidades uma vez que têm acesso ao conhecimento de base tecnológica, mais valorizado pelo mercado.

Acredita-se que essa dinâmica perversa contribui para que haja cada vez mais um abismo no Brasil entre as IES de ensino, geralmente Faculdades privadas e IES de pesquisa, em geral Universidades públicas. Como é previsível, os impactos são negativos para a sociedade, comprometendo, inclusive, o avanço tecnológico em todas as áreas e, consequentemente, o desenvolvimento econômico. Para reverter essa tendência, é imprescindível que se estudem formas de se equacionar as políticas de estímulo à pesquisa e produção acadêmica docente, para evoluir além do atendimento legal ou focado no produtivismo de carreira. Gestores e professores precisam entender a pesquisa como fator de melhoria na formação da educação superior.

\section{O DELINEAMENTO DA PESQUISA}

O estudo de campo realizado utilizou um questionário estruturado on-line, construído com a ferramenta de formulários do Google. A ferramenta foi escolhida para facilitar o acesso aos participantes, assim como para obter melhor acurácia dos dados, que foram armazenados em planilha gerada pela própria ferramenta e posteriormente tabulados, destacando-se que, em nenhum momento, há a identificação do sujeito ou da IES. Como referencial para elaboração de algumas questões, foram utilizados os critérios definidos no instrumento de avaliação de cursos do INEP (2015). 
Os sujeitos escolhidos para compor a amostra foram os docentes em atuação na Educação Superior, independente da IES, sendo que a amostra foi composta a esmo. Esse tipo de amostragem, segundo Costa Neto (1977), caracteriza-se por ser aleatória sem, no entanto, realizar propriamente o sorteio, obtendo resultados equivalentes aos de uma amostragem probabilística. A aleatoriedade é possibilitada pelo acesso livre do respondente via web que, também, garante seu anonimato. Os sujeitos foram convidados para participar da pesquisa via grupos de discussão do Yahoo, Linkedin, Twitter e listas de e-mail de professores.

Para a análise dos dados, o questionário foi estruturado utilizando-se de uma escala nominal que, segundo Marconi e Lakatos (2002), visam a transformar fatos qualitativos em quantitativos ou variáveis para serem mensuradas, no caso da escala nominal em categorias específicas.

Nas questões relacionadas à afinidade com a pesquisa e ambiente para a pesquisa, foram dispostas em afirmações, em que o respondente, por meio da escala Likert, escolhia entre: 1- Discordo totalmente, 2- Discordo, 3- Discordo pouco, 4- Concordo pouco, 5-Concordo, 6-Concordo totalmente.

Buscando uma análise mais apurada das informações coletadas, bem como captar da melhor forma possível as percepções dos respondentes, optou-se por se utilizar um Índice de Concordância (IC), no qual foram atribuídos pesos a cada resposta da seguinte forma: peso 1 para discordo totalmente, peso 2 para discordo, peso 3 para discordo pouco, peso 4 para concordo pouco, peso 5 para concordo e peso 6 para concordo totalmente.

Dessa forma, em cada questão, o número de respondentes foi multiplicado pelo peso da resposta. Para apurar o índice de concordância, o somatório dos pesos, multiplicado pelo número de respondentes de cada questão, é dividido pelo total de respondentes da amostra multiplicado pelo peso máximo possível, seis.

\section{A PERCEPÇÃO DOS DOCENTES}

O questionário on-line ficou disponível no período de setembro de 2015 a novembro de 2015. Os convites foram iniciados pelo Linkedin e, posteriormente, em vários grupos de discussão na mesma rede social, dentre eles: Avaliação Institucional - Ensino Superior (1.935 membros); Docentes em Instituições de Ensino Superior (35.428 membros); Gestão Educacional Privada e Gestores (9.905 membros); Community of Brazilian MBA Professors (2.218 membros); Educar Trabalho (943 membros) e Portal dos Educadores (10.592 membros). Foram feitos ainda convites 
pelo Twitter, assim como por e-mail para lista de contatos de docentes. Estima-se que ao todo o convite ficou acessível à cerca de 80 mil docentes, podendo estes ter sido impactados mais de uma vez ou mesmo não terem notado a publicação.

Foram respondidos ao todo 322 questionários, sendo que sete deles foram desconsiderados por não terem aceitado o Termo de Consentimento Livre Esclarecido (TCLE), constituindo-se em 315 o número total da amostra. Um ponto que pode denotar o interesse dos respondentes pelo assunto e a relevância do tema é o fato de $70 \%$ deles terem deixado seus endereços de e-mail (que era opcional) para receberem os resultados da pesquisa.

A Tabela 1, a seguir, apresenta uma síntese da abrangência da amostra.

Tabela 1 - Abrangência da amostra

\begin{tabular}{lcc} 
& Quantidade & \% \\
\hline Unidades da Federação & 26 & 96 \\
Regiões & 5 & 100 \\
Respostas em Cidades do Interior & 130 & 41 \\
Respostas em Capitais e Regiões Metropolitanas & 185 & 59 \\
\hline
\end{tabular}

Fonte: elaborada pelos autores.

As informações da Tabela 1 reforçam a representatividade da amostra, mesmo que em caráter não probabilístico. No que tange à abrangência, verificou-se que houve ao menos um respondente em cada unidade da federação, exceto do Estado de Rondônia, abarcando assim todas as regiões brasileiras. A distribuição por região se deu da seguinte forma: sudeste com $66 \%$, centro-oeste com $14 \%$, nordeste com $8 \%$ e sul e norte com $6 \%$ do número de respondentes. Na distribuição por unidades federativas, apesar de grande fragmentação das respostas, destacam-se algumas unidades com maior ocorrência: São Paulo com 43\%, Minas Gerais com 18\%, Mato Grosso do Sul com 7\% e Distrito Federal, Rio de Janeiro e Paraná com 4\% cada uma.

Buscando traçar um perfil geral da amostra obtida, a Tabela 2 a seguir apresenta as maiores ocorrências das características dos respondentes. 
Tabela 2 - Perfil dos respondentes

\begin{tabular}{llcc} 
Característica & Resposta & Respondentes $\mathbf{N = 3 1 5}$ & $\mathbf{\%}$ \\
\hline Faixa Etária & 41 a 50 anos & 105 & 33 \\
Sexo & Masculino & 163 & 52 \\
Formação & Licenciaturas e Pedagogia & 94 & 30 \\
Titulação & Mestrado & 137 & 43 \\
Atuação em IES & Privada & 230 & 73 \\
Tempo de Magistério Total & Entre 10 e 20 anos & 107 & 34 \\
Tempo de Magistério Educação Superior Entre 10 e 20 anos & 99 & 31 \\
Atividade Profissional & Não & 164 & 52 \\
Atividade Acadêmica & Sim & 253 & 80 \\
\hline
\end{tabular}

Fonte: elaborada pelos autores.

Analisando o perfil da amostra, convém explicitar os aspectos relevantes. Com relação à faixa etária, apesar de a ocorrência maior estar entre 41 e 50 anos, um grupo relevante, correspondente a 32\% está entre 31 e 40 anos, e o restante com menos de 30 anos, o que indica uma distribuição homogênea entre as faixas.

Quanto à formação, trata-se de uma amostra bastante heterogênea, com 61 especificidades em todas as grandes áreas do conhecimento, o que pode ser positivo para o estudo, uma vez que não sofreu influências de áreas ou atividades específicas. Nas licenciaturas, a maior ocorrência foi em Pedagogia com 9\% do total de respondentes, seguida de Ciências Biológicas com 6\%. Nas demais formações, destacam-se Administração, com $14 \%$ dos respondentes, seguida pelo conjunto das Engenharias, com 7\%.

Com relação à titulação, a distribuição ficou da seguinte forma: Doutorado com 29\%, Mestrado com 43\%, Especialização com 26\% e Graduado com 1\%, dessa forma, $72 \%$ dos respondentes possuem titulação obtida em programas de pós-graduação stricto sensu e 99\% possui pós-graduação. No tipo de vínculo e atuação em IES, 73\% declararam vínculo com IES privadas, 29\% com IES públicas e 8\% com ambas.

Na análise da experiência, tempo de atuação no magistério, nota-se que a maioria dos pesquisados possuem mais de 5 anos de exercício do magistério, o que remete a uma experiência e condições de se posicionar sobre seu trabalho na educação superior.

Considerando as características da amostra apresentada, infere-se que os respondentes reúnem condições favoráveis ao desenvolvimento de pesquisa e produção acadêmica, pois fica evidenciado que possuem senioridade e titulação necessárias. 
Além disso, considera-se que os respondentes podiam com suas percepções contribuir para os resultados deste estudo, pois se constatou que $80 \%$ declararam exercer outras atividades acadêmicas além da docência, assim como, 52\% atuar exclusivamente na área acadêmica.

Dentre os tipos de atividades acadêmicas exercidas, 43\% estão relacionadas a atividades de Orientação, aspecto este relevante, levando em conta a qualidade dos trabalhos produzidos. Se o docente orienta pesquisa de Iniciação científica e para Trabalhos de Conclusão de Curso (TCC) imbuído do desejo de produzir conhecimento (então, só cumprir uma exigência acadêmica) e utilizando a metodologia científica, esse trabalho pode ter qualidade e, ainda, ser publicado em coautoria. Se a Iniciação Científica e o TCC estiverem alinhados com seus interesses de pesquisa, podem dar respaldo a trabalhos futuros, o que é bastante desejável.

A Tabela 3, a seguir, apresenta a distribuição da carga horária semanal, declarada pelos respondentes, destacando-se que os intervalos de carga horária tiveram como referência o instrumento de avaliação de cursos do INEP (2015).

Tabela 3 - Distribuição carga horária semanal

\begin{tabular}{lcccc}
\hline & \multicolumn{2}{c}{ Carga Horária Total } & \multicolumn{2}{c}{ Carga Horária de Pesquisa } \\
\hline Zero & & & 88 & $28 \%$ \\
1 a 11 horas semanais & 35 & $11 \%$ & 161 & $51 \%$ \\
12 a 20 horas semanais & 46 & $15 \%$ & 49 & $16 \%$ \\
21 a 30 horas semanais & 35 & $11 \%$ & 10 & $3 \%$ \\
31 a 40 horas semanais & 101 & $32 \%$ & 5 & $2 \%$ \\
mais de 40 horas semanais & 98 & $31 \%$ & 2 & $1 \%$ \\
\hline
\end{tabular}

Fonte: Elaborada pelos autores.

Com base na distribuição apresentada, pode-se dizer que o perfil médio dos respondentes possui mais de 30 horas semanais no total e dedica até 20 horas às atividades de pesquisa. Ressalta-se que $28 \%$ dos pesquisados declararam não possuir nenhuma hora de dedicação à pesquisa, assim como, apenas $5 \%$ dos pesquisados informam dedicar mais de 20 horas à pesquisa. Corroborando o exposto, quando questionados se a quantidade de horas dedicadas à pesquisa é suficiente, $79 \%$ responderam que não.

Realizada a caracterização da amostra, a seguir são analisadas as informações que buscaram captar as percepções dos respondentes acerca da atividade de pesquisa 
e sua afinidade com esta, a capacitação e o ambiente para a pesquisa, lembrando que se utilizou o índice de concordância (IC), detalhado anteriormente na metodologia. Na Tabela 4 , são apresentadas as percepções acerca da atividade de pesquisa.

Tabela 4 - Identificação com atividades de pesquisa

\begin{tabular}{|c|c|c|c|c|c|c|c|c|}
\hline Afirmações / Respostas ( $\mathrm{N}=315$ ) & 1 & 2 & 3 & 4 & 5 & 6 & IC & IP \\
\hline $\begin{array}{l}\text { A pesquisa é importante na atuação } \\
\text { docente }\end{array}$ & 1 & 2 & 7 & 12 & 51 & 242 & $94 \%$ & 0 \\
\hline $\begin{array}{l}\text { A pesquisa é uma forma de criação do } \\
\text { conhecimento }\end{array}$ & 1 & 2 & 2 & 6 & 53 & 251 & $96 \%$ & O \\
\hline $\begin{array}{l}\text { A atividade de pesquisa pode melhorar a } \\
\text { atuação como docente }\end{array}$ & 1 & 4 & 4 & 19 & 73 & 214 & $92 \%$ & ح \\
\hline Gosto de pesquisar & 1 & 1 & 7 & 21 & 72 & 213 & $92 \%$ & 0 \\
\hline $\begin{array}{l}\text { É mais agradável desenvolver atividades } \\
\text { de pesquisa do que ministrar aulas }\end{array}$ & 33 & 52 & 60 & 91 & 43 & 36 & $59 \%$ & 0 \\
\hline $\begin{array}{l}\text { Gosto de fazer orientação de trabalhos } \\
\text { e de projetos que possam resultar em } \\
\text { alguma produção }\end{array}$ & 2 & 2 & 10 & 32 & 103 & 166 & $89 \%$ & 0 \\
\hline
\end{tabular}

Fonte: Elaborada pelos autores

Legenda: 1- Discordo totalmente; 2- Discordo; 3- Discordo pouco; 4- Concordo pouco; 5- Concordo; 6- Concordo totalmente

A análise das informações permite dizer que os respondentes, de forma geral, acreditam na importância da pesquisa para a atuação docente e como forma de criação do conhecimento, assim como concordam que a pesquisa pode melhorar sua atuação como docente. Com um IC de 92\%, os respondentes manifestaram gosto pessoal pela atividade de pesquisa. Entretanto não é possível afirmar que há uma preferência por essa atividade uma vez que, quando comparada a atividade de pesquisa com a de docência, especificamente, no que tange a ministrar aulas, o IC aponta 59\%. Fica ainda evidente que existe a percepção, por parte do docente, de que a orientação de trabalhos pode resultar em produções e seu gosto por essa atividade, com IC de 89\%.

A seguir, a Tabela 5 apresenta as percepções coletadas acerca do conhecimento de alguns aspectos relativos à pesquisa e produção acadêmica, como regras de elaboração de trabalhos, regras de publicações científicas, fontes de financiamento ou fomento, além do aspecto relacionado à organização do tempo e à necessidade de capacitação para a pesquisa. 
Tabela 5 - Capacitação para a pesquisa

\begin{tabular}{|c|c|c|c|c|c|c|c|c|}
\hline Afirmações / Respostas ( $\mathrm{N}=315$ ) & 1 & 2 & 3 & 4 & 5 & 6 & IC & IP \\
\hline $\begin{array}{l}\text { Tenho conhecimento a respeito de } \\
\text { métodos e de técnicas de elaboração de } \\
\text { trabalhos científicos }\end{array}$ & 2 & 6 & 13 & 34 & 97 & 163 & $87 \%$ & 0 \\
\hline $\begin{array}{l}\text { Conheço as regras de publicação em } \\
\text { periódicos científicos }\end{array}$ & 4 & 15 & 19 & 58 & 90 & 129 & $82 \%$ & 0 \\
\hline $\begin{array}{l}\text { Conheço as fontes de financiamento ou } \\
\text { fomento à pesquisa }\end{array}$ & 13 & 33 & 35 & 77 & 83 & 74 & $71 \%$ & 0 \\
\hline $\begin{array}{l}\text { Já utilizei fontes de financiamento ou } \\
\text { fomento à pesquisa }\end{array}$ & 131 & 18 & 17 & 14 & 29 & 106 & $56 \%$ & O \\
\hline $\begin{array}{l}\text { Utilizo periódicos científicos e consulto } \\
\text { bases de dados em minhas pesquisas }\end{array}$ & 16 & 6 & 17 & 24 & 55 & 197 & $86 \%$ & 0 \\
\hline $\begin{array}{l}\text { Considero que organizar o tempo é uma } \\
\text { dificuldade para exercer a atividade de } \\
\text { pesquisa }\end{array}$ & 17 & 25 & 34 & 69 & 91 & 79 & $73 \%$ & 0 \\
\hline $\begin{array}{l}\text { É importante que o docente participe de } \\
\text { um programa de capacitação voltado à } \\
\text { pesquisa }\end{array}$ & 3 & 5 & 7 & 26 & 82 & 192 & $90 \%$ & 0 \\
\hline
\end{tabular}

Fonte: Elaborada pelos autores

1-Discordo totalmente; 2- Discordo; 3- Discordo pouco; 4-Concordo pouco; 5-Concordo; 6-Concordo totalmente

É possível afirmar que há um elevado nível de conhecimento sobre as regras de elaboração e publicação em periódicos científicos, assim como a utilização e acesso a periódicos e bases de dados. Porém há um ponto de atenção com relação às fontes de financiamento e/ou fomento à pesquisa, apesar de um IC de $71 \%$ quanto ao conhecimento dessas fontes, o índice cai para $56 \%$ quando a questão é sobre a utilização desses recursos.

Em linhas gerais, os respondentes declaram ter os conhecimentos necessários para a pesquisa, mas, ao mesmo tempo, com IC de $90 \%$, acreditam que é importante que o docente participe de um programa de capacitação voltado à pesquisa, o que evidencia a necessidade de ações dentro das IES para suprir essa lacuna, o que vem ao encontro de outro estudo realizado por Carvalho (2015) sobre essa necessidade.

Um ponto que merece destaque é o fato de boa parte dos respondentes indicarem, com IC de 73\%, que organizar o tempo é uma dificuldade para desenvolver 
atividades de pesquisa, assim como já apontado anteriormente, 79\% afirmaram considerar insuficiente o número de horas semanais dedicadas à pesquisa. Isso traz à tona a questão que merece melhor investigação: seria o problema a quantidade de horas insuficiente ou a organização do tempo para pesquisa, ou ambas? Considera-se que essa questão merece atenção por parte das IES.

Na Tabela 6, a seguir, são apresentadas as percepções dos respondentes, com base em sua realidade, acerca do ambiente para a pesquisa.

Tabela 6 - Ambiente para a pesquisa

\begin{tabular}{|c|c|c|c|c|c|c|c|c|}
\hline Afirmações / Respostas (N=315) & 1 & 2 & 3 & 4 & 5 & 6 & IC & IP \\
\hline Há incentivo para pesquisar & 86 & 61 & 55 & 65 & 30 & 18 & $47 \%$ & O \\
\hline $\begin{array}{l}\text { Há orientação quanto ao direcionamento } \\
\text { para o desenvolvimento de pesquisas }\end{array}$ & 72 & 65 & 56 & 72 & 34 & 16 & $49 \%$ & 0 \\
\hline $\begin{array}{l}\text { Há tempo disponível em minha carga } \\
\text { horária semanal para exercer a atividade } \\
\text { de pesquisa }\end{array}$ & 99 & 55 & 47 & 48 & 37 & 29 & $48 \%$ & 0 \\
\hline $\begin{array}{l}\text { Recebi apoio financeiro para participação } \\
\text { em eventos científicos com apresentação } \\
\text { de trabalhos }\end{array}$ & 167 & 50 & 22 & 28 & 22 & 26 & $38 \%$ & 0 \\
\hline $\begin{array}{l}\text { Tive dificuldades quando utilizei fontes de } \\
\text { financiamento ou fomento à pesquisa }\end{array}$ & 127 & 42 & 41 & 33 & 36 & 36 & $46 \%$ & 0 \\
\hline $\begin{array}{l}\text { Onde atuo existe um ambiente facilitador } \\
\text { para troca de ideias, informações, } \\
\text { conhecimento e colaboração em projetos } \\
\text { para o corpo docente }\end{array}$ & 66 & 60 & 51 & 60 & 39 & 39 & $53 \%$ & 0 \\
\hline $\begin{array}{l}\text { O acervo disponível biblioteca, incluindo } \\
\text { periódicos e acesso às bases de dados, } \\
\text { é suficiente para o desenvolvimento de } \\
\text { pesquisas }\end{array}$ & 49 & 41 & 53 & 51 & 73 & 48 & $61 \%$ & 0 \\
\hline $\begin{array}{l}\text { Acredito na necessidade de um programa } \\
\text { interno onde atuo, de fomento à pesquisa } \\
\text { acadêmica docente }\end{array}$ & 15 & 12 & 17 & 24 & 73 & 174 & $84 \%$ & 0 \\
\hline
\end{tabular}

Fonte: Elaborada pelos autores

Legenda: 1- Discordo totalmente; 2- Discordo; 3- Discordo pouco; 4- Concordo pouco; 5- Concordo; 6- Concordo totalmente

As informações da Tabela 6 indicam que há necessidade de melhoria nos aspectos mais críticos, são eles: ao apoio financeiro para participação em eventos 
científicos (IC de 38\%) e dificuldade na utilização de fontes de financiamento e/ou fomento à pesquisa, com IC de $46 \%$. Ficou evidente ainda que o incentivo à pesquisa, orientação quanto ao desenvolvimento de pesquisas, ambiente que propicie a troca de ideias e, novamente, o fator tempo e carga horária disponível para pesquisa são pontos que carecem de atenção.

O incentivo à pesquisa mais que estar ligado ao suporte financeiro, precisa estar respaldado em políticas, projetos e programas que o articule à atividade docente. A necessidade de uma liderança que organize o desenvolvimento das pesquisas é de extrema importância. A organização, nesse caso, compreenderia a proposição ou seleção de pesquisas alinhadas às necessidades locais, onde a IES está inserida ou, mesmo, aos planos e políticas de desenvolvimento institucional de sua IES. Essa organização funcionaria como um facilitador para obtenção de recursos, assim como contribuiria para inserção social da IES e, consequentemente, para o reconhecimento da pesquisa, tanto pela comunidade acadêmica como pela sociedade.

Importante destacar que o ambiente da IES, fundamental para desenvolvimento de pesquisas e criação do conhecimento, extrapola o simples conceito de espaço físico, portanto, envolve relacionamentos, interações, troca de ideias e experiências. Nesse sentido, quando levantada a questão de um ambiente facilitador para troca de ideias, informações e conhecimento, o IC atingiu apenas 53\%. Esse ponto traz à tona a necessidade não apenas da IES realizar ações para promover a pesquisa acadêmica docente, mas também para promover a interdisciplinaridade ou mesmo a transdisciplinaridade, buscando romper o paradigma de compartimentalização de disciplinas e áreas do conhecimento. Dessa forma, haverá espaço para interações e relacionamentos que possam gerar frutos em pesquisas.

A disponibilidade de acervo e acesso às bases de dados, apesar de um IC de $61 \%$, denota que ainda há espaço para melhoria. Isso pode estar relacionado ao fato de que, em geral, quando não há programa de pós-graduação stricto sensu na IES, tanto as bases de dados quanto o acervo acabam sendo restritos ao atendimento da graduação, o que, muitas vezes, para determinadas pesquisas, pode não atender a necessidade do docente enquanto pesquisador ou limitar sua atuação.

Com IC 84\%, é percebido que os respondentes acreditam na necessidade de um programa interno em sua IES para fomento à pesquisa acadêmica docente. Cabe destacar que a concordância com a afirmação não necessariamente significa que a IES não tenha projetos, políticas ou ações com o objetivo de estimular a pesquisa acadêmica docente. Denota que as ações realizadas pelo programa, visando atender 
às condições para a realização de pesquisas não são percebidas como tal. Essa falta de percepção remete à necessidade de, mais que oferecer condições, publicizar, reiteradamente, como ter acesso a essas condições.

\section{CONSIDERAÇÕES FINAIS}

A pesquisa e a produção acadêmica docente no contexto das IES brasileiras constituem tema abrangente e trazem consigo pontos controversos, incluindo sua exigência como requisito legal previsto no SINAES, por meio das avaliações de curso, em todas as categorias de organização das instituições. Este artigo buscou tratar parte dos aspectos que envolvem essa produção na realidade da graduação presencial, sob o ponto de vista dos docentes. Com base em suas impressões e percepções, buscou-se inferir possíveis ações que possam levar à melhoria dessa produção, consequentemente, da atuação docente e da formação do estudante da educação superior.

Ficou evidente que existe, por parte dos docentes, a percepção da importância da atividade de pesquisa em sua prática, indo ao encontro do que foi abordado no referencial teórico. Ao mesmo tempo, é nítido que não há, na visão dos pesquisados, políticas claras de incentivo à pesquisa e à produção acadêmica. Da mesma forma, há insatisfação com a carga horária para atividade de pesquisa e dificuldade em organizar o tempo para a realização dessa atividade, o que leva a crer que o aumento simplesmente de carga horária para esse fim pode não surtir efeitos.

Com relação ao ambiente oferecido para a execução das atividades de pesquisa, é necessário que haja não apenas uma estrutura física, mas condições adequadas e liderança, que organize e promova a troca de ideias e de experiências; e pesquisas multidisciplinares, voltadas à realidade local. O incentivo ao trabalho em grupo, cooperativo, poderia despertar o interesse do estudante da graduação pela pesquisa.

Acredita-se que um importante alerta trazido pelas percepções e possível alvo de novas estratégias por parte das IES que anseiem por melhoria da produção acadêmica é a constituição de uma política ampla que abarque capacitação, incentivos, orientação e direcionamento para o exercício adequado dessa atividade. Assim, a sinergia dessas estratégias poderá produzir resultados, o que dificilmente ocorre com ações isoladas.

O que se pretende com a abordagem, aqui exposta, é ampliar e aprofundar a discussão sobre a produção acadêmica no âmbito da graduação nas IES. Essa é uma questão complexa e relevante, cujo desvelamento e enfrentamento, por parte da comunidade acadêmica podem contribuir para uma melhoria da formação na educação superior. 


\section{REFERÊNCIAS}

BRASIL. Decreto n. 5.773, de 9 de maio de 2006. Dispõe sobre o exercício das funções de regulação, supervisão e avaliação de instituições de educação superior e cursos superiores de graduação e sequenciais no sistema federal de ensino. Diário Oficial [da] República Federativa do Brasil, Poder Executivo, Brasília, DF, 10 maio 2006a.

. Decreto n. 5.786, de 24 de maio de 2006. Dispõe sobre os centros universitários e dá outras providências. Diário Oficial [da] República Federativa do Brasil, Poder Executivo, Brasília, DF, 25 maio 2006b.

. Lei n. 9.394, de 20 de dezembro de 1996. Estabelece as diretrizes e bases da educação nacional. Diário Oficial [da] República Federativa do Brasil, Poder Executivo, Brasília, DF, 23 dez. 1996.

CARVALHO, Alexey. Pesquisa e trabalho docente na educação superior. In: CONGRESO DE LA INTERNACIONAL DEL CONOCIMIENTO: CIENCIAS, TECNOLOGIAS Y CULTURAS - MIRANDO AL FUTURO DE AMERICA LATINA E EL CARIBE, 4., 10 out. 2015, Santiago do Chile. Simpósio n. 67. Santiago do Chile: Universidad de Santiago de Chile (USACH), 2015.

CHARLOT, Bernard. Texto apresentado no II Fórum Social Mundial pelo Fórum Mundial de Educação. Porto Alegre, 2001.

COSTA NETO, Pedro L. O. Estatística. São Paulo: Edgard Blücher, 1977. 264p.

DEMO, Pedro. Educar pela pesquisa. Campinas, SP: Autores Associados, 1996.

DIAS SOBRINHO, José. Democratização, qualidade e crise da Educação Superior: faces da exclusão e limites da inclusão. Educação e Sociedade, Campinas, SP, v. 31, n. 113, p. 122345, out./dez. 2010.

Avaliação da educação superior. Petrópolis, RJ: Vozes, 2000.

INSTITUTO NACIONAL DE ESTUDOS E PESQUISAS EDUCACIONAIS ANÍSIO TEIXEIRA (INEP). Instrumento de avaliação de cursos de graduação presencial e a distância. Brasília, DF, mar. 2015. Disponível em: <http://download.inep.gov.br/educacao_superior/avaliacao_cursos_ graduacao/instrumentos/2015/instrumento_avaliacao_cursos_graduacao_presencial_distancia.pdf>. Acesso em: 7 abr. 2015.

. Resumos Técnicos - Censo da Educação Superior 2012. Disponível em: <http://portal. inep.gov.br/web/censo-da-educacao-superior/resumos-tecnicos>. Acesso em: 27 abr. 2016. MARCONI, Marina de A.; LAKATOS, Eva Maria. Técnicas de pesquisa. 5. ed. São Paulo: Atlas, 2002.

\section{Sobre os autores:}

Alexey Carvalho: Doutor em Educação pela Universidade de Sorocaba (UNISO), Mestre em Tecnologia pelo Centro Paula Souza e Administrador. Professor e Diretor 
Executivo da Universidade Anhanguera de São Paulo (UNIAN-SP). Suas pesquisas tratam sobre avaliação da educação superior, gestão da educação superior e educação à distância. E-mail: alexeycarvalho@gmail.comm

Maria Alzira de Almeida Pimenta: Doutora em Educação pela Universidade Estadual de Campinas, Mestre em Artes pela Universidade de São Paulo. Professora do Programa de Pós-graduação em Educação da Universidade de Sorocaba (UNISO). Suas pesquisas tratam sobre avaliação da aprendizagem, fraude acadêmica e ética. E-mail: alzira.pimenta@gmail.com

\section{Recebido em junho de 2017}

Aprovado para publicação em junho de 2017. 
